\title{
Cardiac amyloidosis: a review of the literature and a practical approach for the clinicians
}

\author{
Annalisa Angelini, ${ }^{1}$ Francesca Zanco, ${ }^{1}$ Chiara Castellani, ${ }^{1}$ Andrea Di Francesco, ${ }^{1}$ Mila Della Barbera, ${ }^{1}$ \\ Giovanni Maria Vescovo, ${ }^{1}$ Tamara Berno, ${ }^{2}$ Marny Fedrigo ${ }^{1}$ \\ ${ }^{1}$ Department of Cardiac Thoracic Vascular Sciences and Public Health; and ${ }^{2}$ Department of Medicine, Hematology and Clinical \\ Immunology Unit, University of Padua, Italy
}

\begin{abstract}
Amyloidosis is a group of progressive and devastating disorders resulting from misfolded proteins extracellular deposition into tissues. When deposition of fibrils occurs in cardiac tissues, this systemic disease can lead to a very poor prognosis. In this review, we focused on the most common types of cardiac amyloidosis and their treatments. Early diagnosis remains critically important, and here we reviewed the diagnostic methods adopted starting from the non-invasive imaging techniques to more invasive approaches, and the typing of precursor proteins. Typing the different misfolding proteins is mandatory since therapy differs accordingly and thus guiding therapy. We highlighted the most updated and recent treatment strategies to cure amyloidosis.
\end{abstract}

\section{Definition and general mechanism}

Amyloidosis is a wide group of protein folding disorders, discovered more than 150 years ago by the German pathologist Rudolf Virchow. ${ }^{1,2}$ They share a common, multiple-factorial pathogenesis characterized by the deposition of insoluble proteinaceous amorphous material mainly in parenchymal organs. Amyloid is deposited as rigid, insoluble, non-branching fibrils, also referred to as a $\beta$-pleated sheet. ${ }^{3}$

Fibrils bind the Congo red dye and exhibit green, yellow or orange birefringence when the stained deposits are viewed by polarization microscopy. When

Correspondence: Annalisa Angelini, Cardiovascular Pathology and Pathological Anatomy Unit, University of Padua, via A. Gabelli 61, 35121 Padova, Italy.

Tel./Fax: +39.049.8272260; +39.049.8212205.

E-mail: annalisa.angelini@unipd.it

Key words: Systemic amyloidosis; cardiac amyloidosis; proteomic; mass spectrometry.

Conflict of interests: the authors declare no conflict of interests.

Received for publication: 12 February 2019.

Accepted for publication: 2 April 2019.

This work is licensed under a Creative Commons Attribution NonCommercial 4.0 License (CC BY-NC 4.0).

CCopyright A. Angelini et al., 2019

Licensee PAGEPress, Italy

Italian Journal of Medicine 2019; 13:73-90

doi:10.4081/itjm.2019.1149 isolated from tissues and analyzed by X-ray diffraction, fibrils exhibit a characteristic cross $\beta$ diffraction pattern.

In 1959 electron microscopy was applied for the first time in the evaluation of the disease and showed the characteristics of non-branching $\beta$-pleated sheets ${ }^{4}$ with fibrillar diameter ranging between 7-12 nm, allowing a clear and reliable differentiation from collagen fibril deposition. In the last ten years, the introduction of mass spectrometry in the amyloid diagnosis and characterization increased progressively the number of recognized precursor proteins involved. Many proteins might form amyloid-like structures and, until now, about 36 proteins have been shown to form amyloid deposits in vivo in humans, according to the Nomenclature Committee of the International Society of Amyloidosis (ISA). ${ }^{5,6}$ In Table 1 we reported all types of precursor proteins that can produce amyloid deposition in the parenchymal organs. ${ }^{7-11}$ The main types of amyloidosis are represented by amyloid light chain (AL) or amyloid heavy chain, in the setting of plasma cell disease producing an increased number of circulating light and heavy chain fragments.

AA amyloidosis is usually secondary to chronic processes such as autoimmune diseases or chronic infections. The amyloid deposition may affect the human body in a systemic or localized manner, impairing progressively the physiological functions in different ways.

Systemic amyloidosis is characterized by the production of amyloidotic precursor proteins remotely from precursor organs in which deposition occurs, while in localized amyloidosis the production of the abnormal precursor proteins occurs in the same site where deposition occurs. Systemic amyloidosis can be acquired (AL amyloidosis), or hereditary (ATTR). wTATTR is also termed senile systemic amyloidosis. 
$\mathrm{AL}$ amyloidosis can also manifest itself as a localized disease, as the tumor-like nodule localized in the larynx, tongue, skin, bladder, bowel, and lung and may affect patients with thyroid tumors, diabetes or advanced age as the only risk factor for localized amyloidosis. ${ }^{4}$

Table 1 showed mainly diseases that were associated with the systemic form. ${ }^{6,8}$

Several types of amyloidosis are hereditary and have been linked to familiar forms. The most common genetic alteration is missense mutation of the precursors of proteins, transthyretin (ATTR) is the most important, cysteine, Apo A1, gelsolin, lysosome, fibrinogen A $\alpha$, ApoAII. ${ }^{12,13}$

The chemical diversity makes the clinical presentation heterogeneous; in fact, different types of amyloid-fibrils demonstrate different tissue affinities and correlate with a variety of symptoms. ${ }^{14}$ Furthermore, individual differences exist for the same type of amyloid. For all these reasons, amyloidosis represents a diagnostic challenge for clinicians. Virtually, every organ system can be affected by amyloid deposition.

A lot of diseases may cause and hide amyloido$\operatorname{sis}^{4,15}$ (Figures 1 and 2).

\section{Cardiac amyloidosis}

Cardiac involvement in amyloidosis is usually part of a systemic disease. The cardiac involvement has a major impact on adverse prognosis and unfortunately, the diagnosis is often delayed. It is initially suspected in a patient presenting with unexplained heart failure symptoms, thus in an advanced disease status.
It is interesting to note that there are some geographic differences in cardiac amyloidosis around the world:

- Developed world: i) AL amyloidosis; ii) senile systemic amyloidosis (SSA); iii) familial amyloidosis (it most commonly results from a mutation in transthyretin).

- Developing world: AA is more prevalent, due to chronic infections and inadequately treated inflammatory conditions.

- Occurring worldwide and later in life: a further amyloid type to affect the heart is isolated atrial amyloid.

- Much less common: non-transthyretin variants (mutations of fibrinogen, apoprotein, and gelsolin: these rarer types can cause significant cardiac compromise).

\section{Amyloid types affecting the heart}

There are 11 types of amyloidosis, of these only the atrial form occurs exclusively in the heart. ${ }^{16}$ The three main types involved are acquired monoclonal AL amyloidosis, hereditary TTR amyloidosis and wild type amyloidosis (SSA). ${ }^{16-20}$

\section{Light chain amyloidosis}

Immunoglobulin light chain amyloidoses are rare, monoclonal plasma cell proliferative disorders characterized by tissue deposits of light chain and more rarely, heavy or heavy/light chain fragments, leading to organ dysfunction.

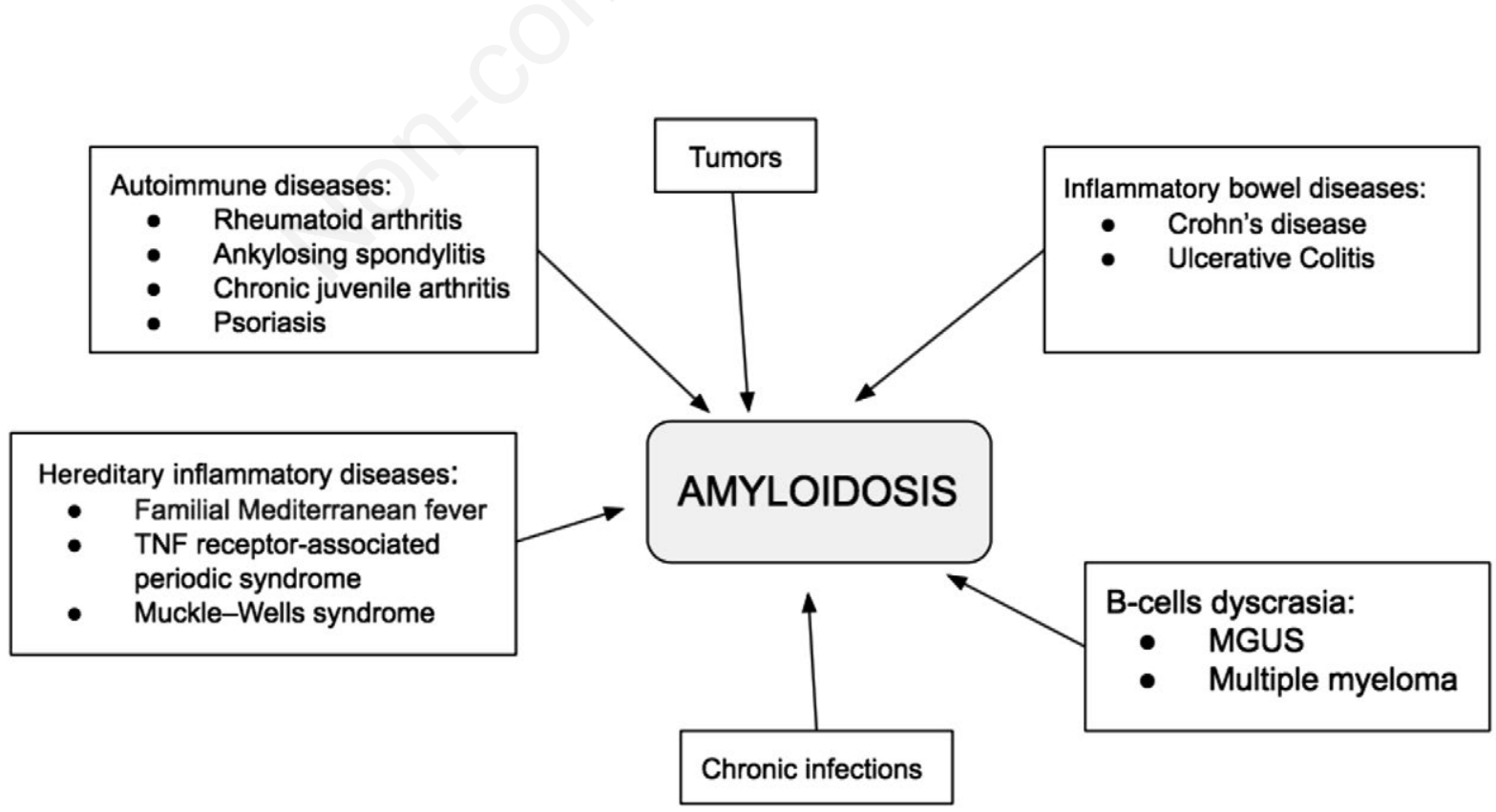

Figure 1. Diseases causing amyloidosis. Chronic systemic diseases could be associated with amyloid deposits in the parenchymal organs, some localized in the target diseased organ or involved multiple parenchymal organs. TNF, tumor necrosis factor; MGUS, monoclonal gammopathy of undetermined significance. 


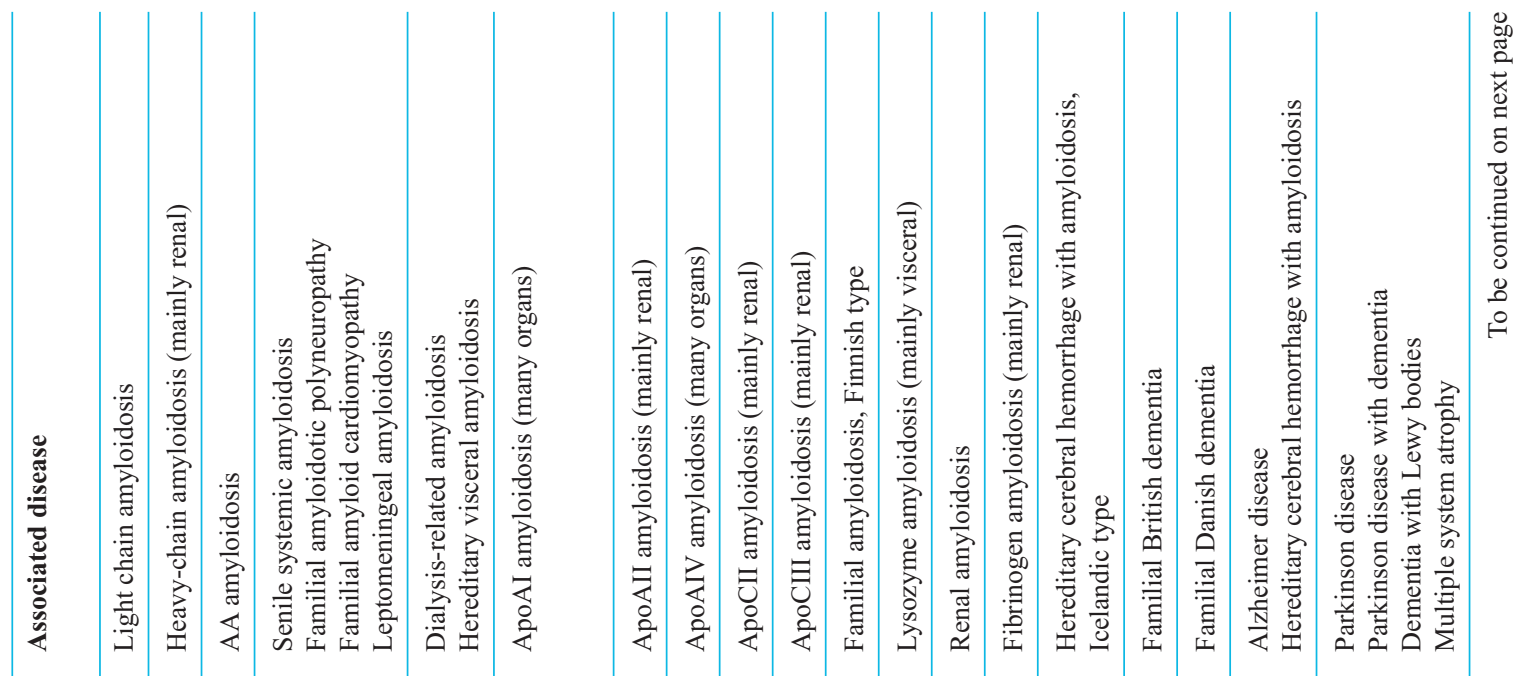

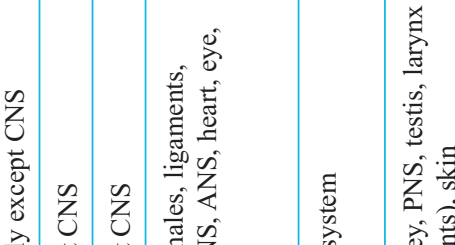

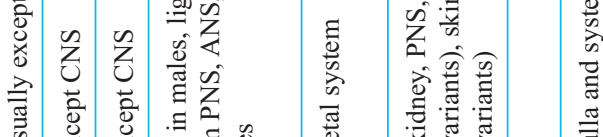

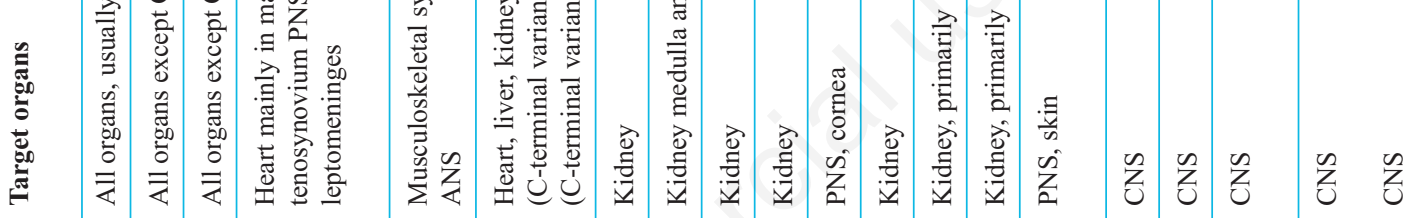

כั)

言密

\begin{tabular}{l|lll|l}
$\Psi$ & 4 & $\varangle$ & $\Psi$ & $\varangle$
\end{tabular}

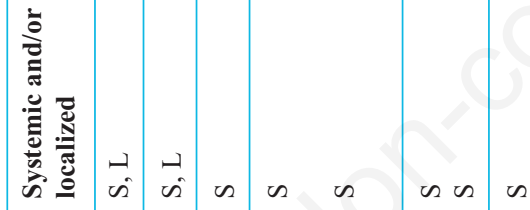

I $\varangle$ I $I$ I $I$ I

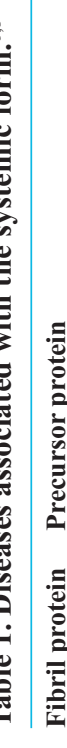

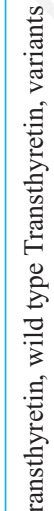

a is us as as on on on

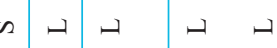




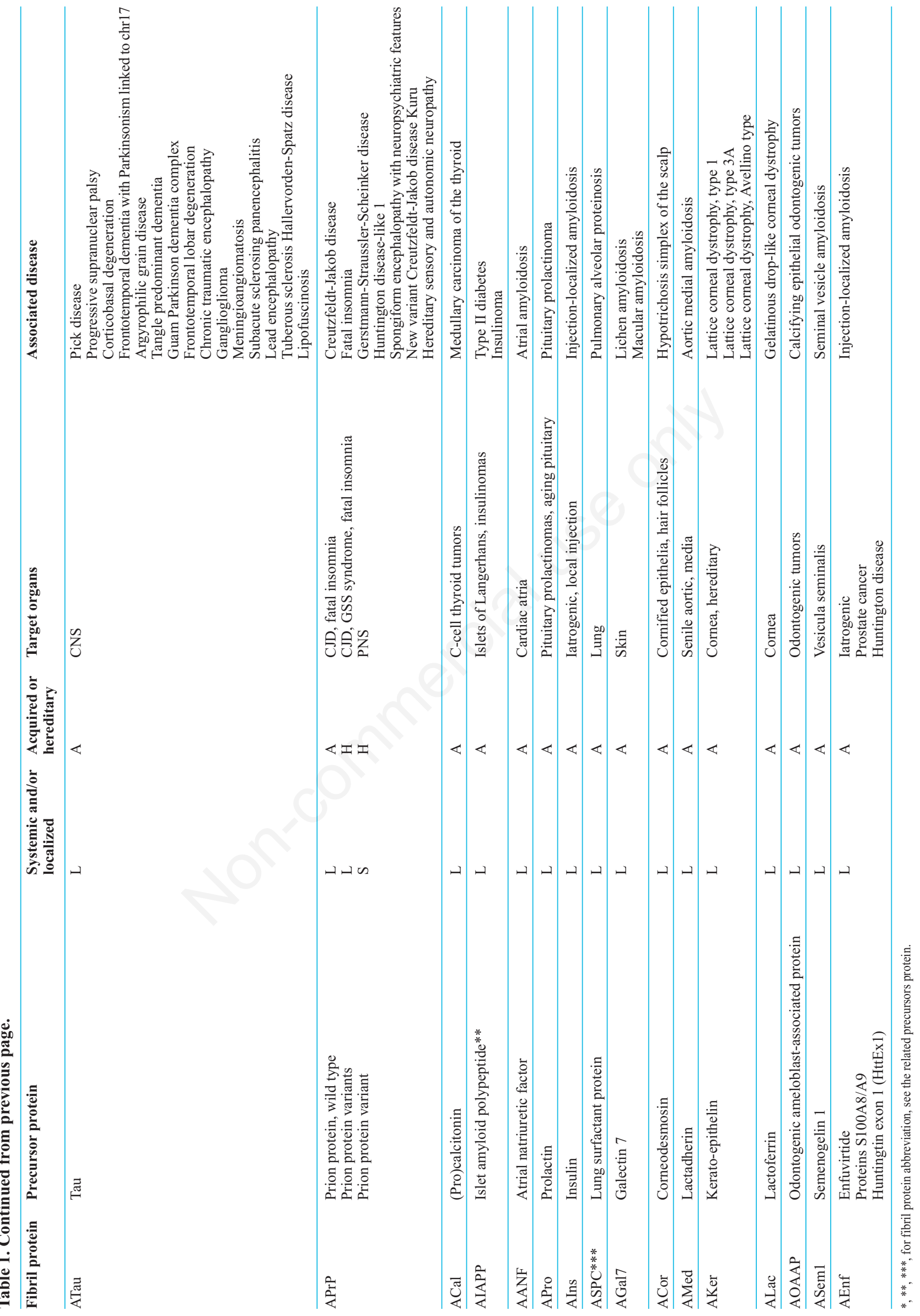


Immunofluorescence techniques reveal the presence of monoclonal plasma cell population in more than $80 \%$ of AL patients.

Among the systemic amyloidoses, the Immunoglobulin light chain ones are the most common with an incidence of 10 patients per million per year. They are also the most severe targeting the heart.

They occur approximately equally in men and women, usually older than 50 years of age.

They could arise as an isolated entity or coexist or be related to a plasma cell dyscrasia status (i.e. multiple myeloma, monoclonal gammopathy of undetermined significance, leukemia).

Less than $1 \%$ of patients with isolated AL amyloidosis at diagnosis will develop multiple myeloma. It is estimated that myeloma may coexist with $\mathrm{AL}$ amyloid in around $10-15 \%$ of cases. In fact, at the time of diagnosis, approximately 10 percent of patients with AL amyloidosis will meet diagnostic criteria for myeloma as defined by CRAB (hypercalcemia, renal insufficiency, anemia or bone marrow disease) criteria; nearly another 40 percent of patients with AL amyloidosis do not meet these criteria but have $10 \%$ or more bone marrow plasmacytosis at diagnosis. The incidence is approximately one-fifth that of multiple myeloma. The clinical course and treatment of these patients is dependent on which of the two diseases is dominant in terms of end-organ damage and symptoms.

In AL amyloid, the plasma cell number, degree of clonality, the quantity of light chain, and the light chain isotype are related to survival.
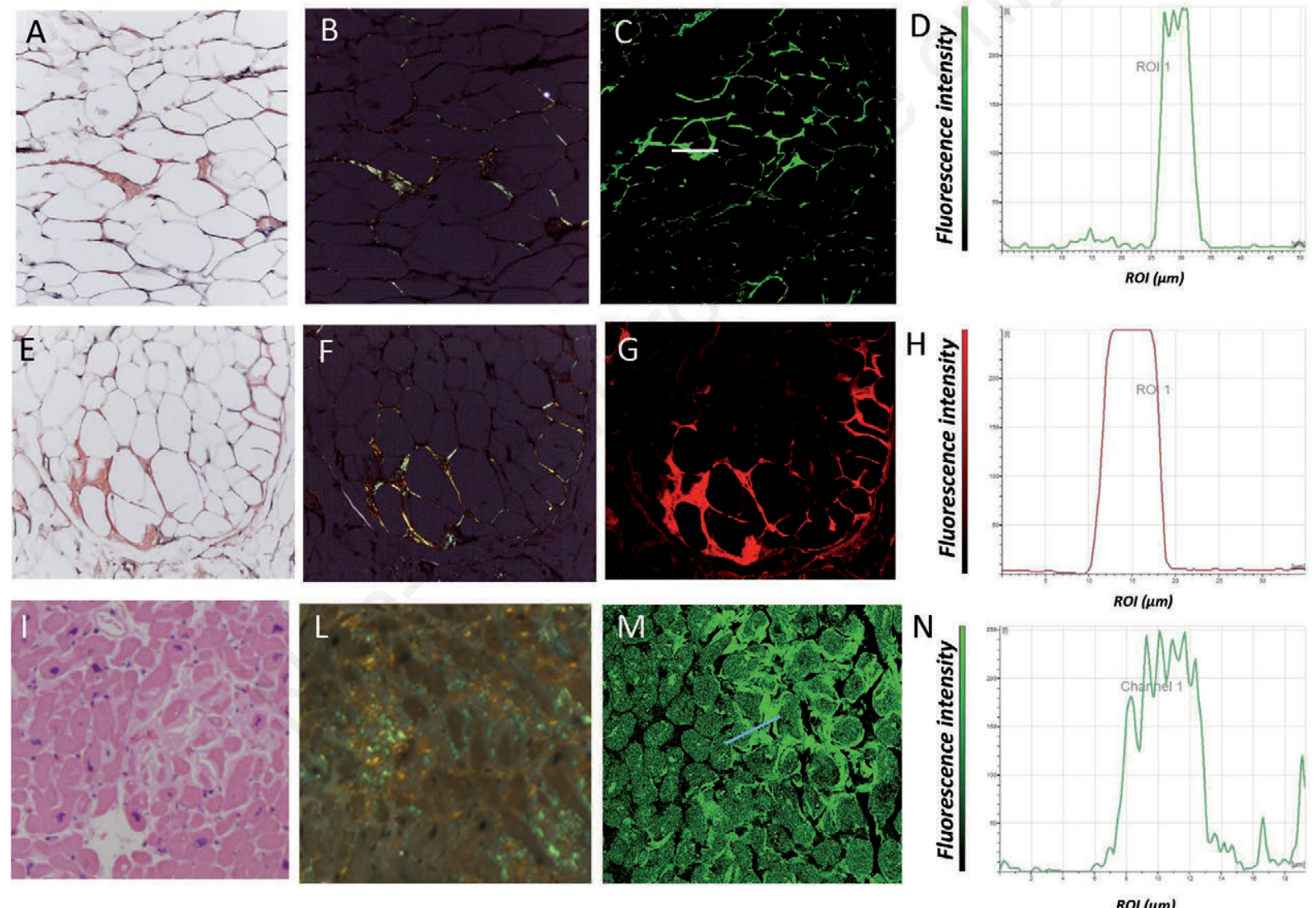

Figure 2. Amyloid histological confirmation. Fat tissue and endomyocardial biopsy on confocal microscopy technique. A-D) Representative images of a fat tissue positive for amyloidosis. Note as Congo-Red staining viewed under polarized light (B) shows very few apple-green deposits. On the contrary the same slides viewed under confocal microscope using Thioflavin T staining show fluorescence of amyloid deposits. A and B) Original magnification 20x; C) original magnification 40x. In d confocal microscope fluorescence profile of ROI (region of interest, white line); E-H) Representative images of fat tissue positive for amyloidosis. Note that Congo-Red staining viewed under polarized light results in applegreen, orange and yellow colors defined as anomalous colors due to the amyloid fibers orientation. Congo-Red staining viewed under confocal microscope instead, in G), shows red fluorescence for amyloid deposits, confirmed also by the fluorescence profile, in $\mathbf{H}$ ). E and F) Original magnification 20x; G) original magnification 40x; I-N) representative images of an endomyocardial biopsy positive for amyloid. Note as Thioflavin- $T$ viewed under confocal microscope, in $M$ ) is better in terms of contrast than Congo-Red staining viewed under polarized light as showed in $L$ ). I and $L$ ) Original magnification 20x; 20x in M). Confocal microscope both for Congo-Red fluorescence and Thioflavin-T staining is better in terms of better contrast and absence of out-of-focus interference. 
In addition to clinical examination and serological tests, the bone marrow biopsy is mandatory in order to determine the percentage of plasma cells.

Usually, there is a predominance of lambda over kappa light chains in a ratio of 3:1 in AL amyloidosis.

In the majority of patients (around 70\%) more than one organ is compromised.

Light chains mostly settle in kidneys (74\%) and heart (60-90\%). Clinically isolated heart involvement is seen in less than $5 \%$ of cases. $20 \%$ of patients have dominant symptomatic cardiac amyloid at diagnosis. ${ }^{21}$

When amyloid involves the vasculature, and particularly intramyocardial small vessels, patients may present with classical exertional angina.

Amyloid deposition can be a very rapidly progressive phenomenon. For instance, myocardial wall thickening can progress at rates between 1.45 and 2.16 $\mathrm{mm} / \mathrm{month}$ in patients with AL amyloid and death can ensue within 6 months. ${ }^{22-25}$

\section{Transthyretin amyloidosis}

Two types of amyloidosis can arise from TTR, a tetrameric protein synthetized primarily in the liver, the wild type (formally known as SSA) which leads more frequently to isolated cardiac amyloidosis and the hereditary amyloidosis which is transmitted as an autosomal dominant pattern and it is the result of mutations of transthyretin gene. Autopsy studies have proved that in a percentage between $22-36 \%$ of individuals older than 80 years demonstrable amyloid deposits in cardiac tissue can occur.

Even this form of amyloid has systemic distribution, but the deposition is predominantly in the heart and impaired renal function may occur late in the disease, when cardiac output is very low.

The patient prototype is an elderly male (older than 65 years) with unexplained ventricular wall thickening noted on echocardiography and clinical biventricular heart failure, sometimes electrocardiogram voltage may be normal, but atrial fibrillation or flutter commonly occur and conduction system disease requiring a permanent pacemaker is a frequent finding.

Transthyretin is the most common protein in the category of hereditary systemic amyloidosis of middle or old age. Around 100 different mutations have now been identified with variable penetrance. $50 \%$ of them involve the heart to a greater or lesser degree. ${ }^{26,27}$

\section{Isolated atrial amyloid (non-light chain and on-hereditary amyloidosis)}

This type is very prevalent in the elderly population, more common in older women. It is of little clinical significance and it is found in patients with chronic heart failure, except perhaps being associated with the development of atrial fibrillation ${ }^{28}$ (Table $2^{29-43}$ ).

\section{When to suspect amyloidosis}

Timeliness in the diagnosis and accurate typing of the amyloid deposits are of primary importance. As already mentioned, making an early diagnosis of amyloidosis is very difficult, because its onset presents multiple and often non-specific symptoms, very common, especially in the elderly.

Anyone can develop amyloidosis. Factors that increase the risk include: age, sex, ethnicity, coexisting diseases, family history, and kidney dialysis: ${ }^{44,45}$

- Age: most people diagnosed with AL amyloidosis, the most common type, are between 60 and 70 years of age, although earlier onset occurs.

- Sex: nearly 70 percent of people with AL amyloidosis are men.

- Other diseases: having a chronic infectious or inflammatory disease increases your risk of AA amyloidosis.

- Family history: some types of amyloidosis are hereditary.

- Kidney dialysis: dialysis cannot always remove large proteins from the blood. If you are on dialysis, abnormal proteins can build up in your blood and eventually be deposited in tissue. This condition is less common with modern dialysis techniques.

- Race: people of African descent appear to be at higher risk of carrying a genetic mutation associated with the type of amyloidosis that can harm the heart. We can consider the diagnostic path leading to the diagnosis of amyloidosis as a three-stage process: i) suspicion; ii) diagnosis; and iii) characterization of the type of amyloid. ${ }^{46}$

\section{Stage I: suspicion}

This is the first and most difficult phase because of the non-specificity of symptoms. A list of red flags to suspect amyloidosis, is: impaired kidney function and/or presence of protein in the urine; swollen ankle; shortness of breath on exertion; fainting; heart failure with poor response to standard treatments; tingling; pain and altered sensation in the hands and feet - glove and stocking neuropathy; changes in bowel habit (diarrhea or constipation $)^{47}$ (Table $3^{48-71}$ ).

\section{Stage II: diagnosis}

\section{Serum biomarkers}

Serum natriuretic peptides and troponin are classically biomarkers associated with the detection and evaluation of heart failure in patients with cardiac amyloidosis; troponin $\mathrm{T}(\mathrm{cTnT})$ is a reliable marker of cardiomyocyte damage and has proven to be a strong negative prognostic factor for overall survival. ${ }^{72}$ 


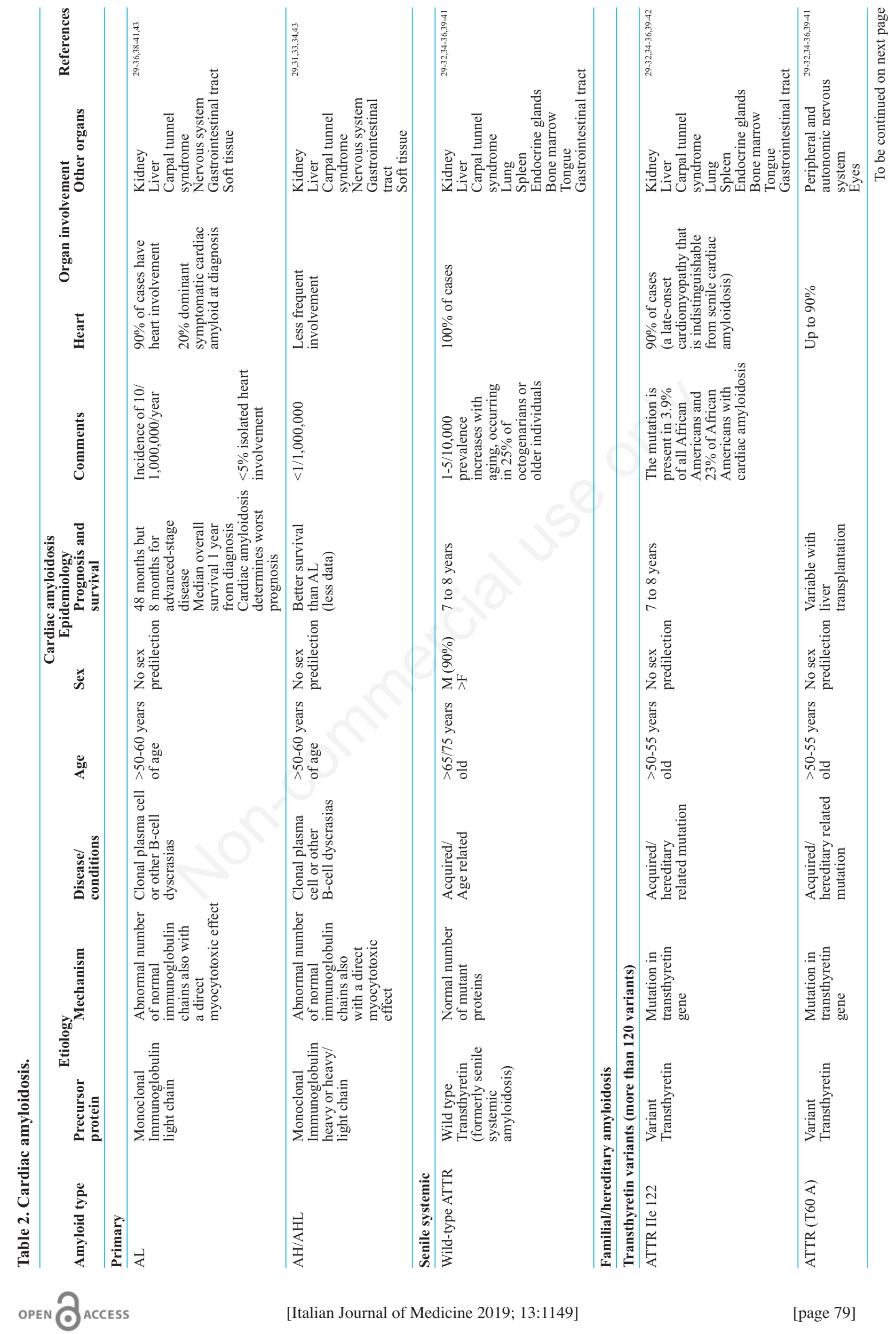




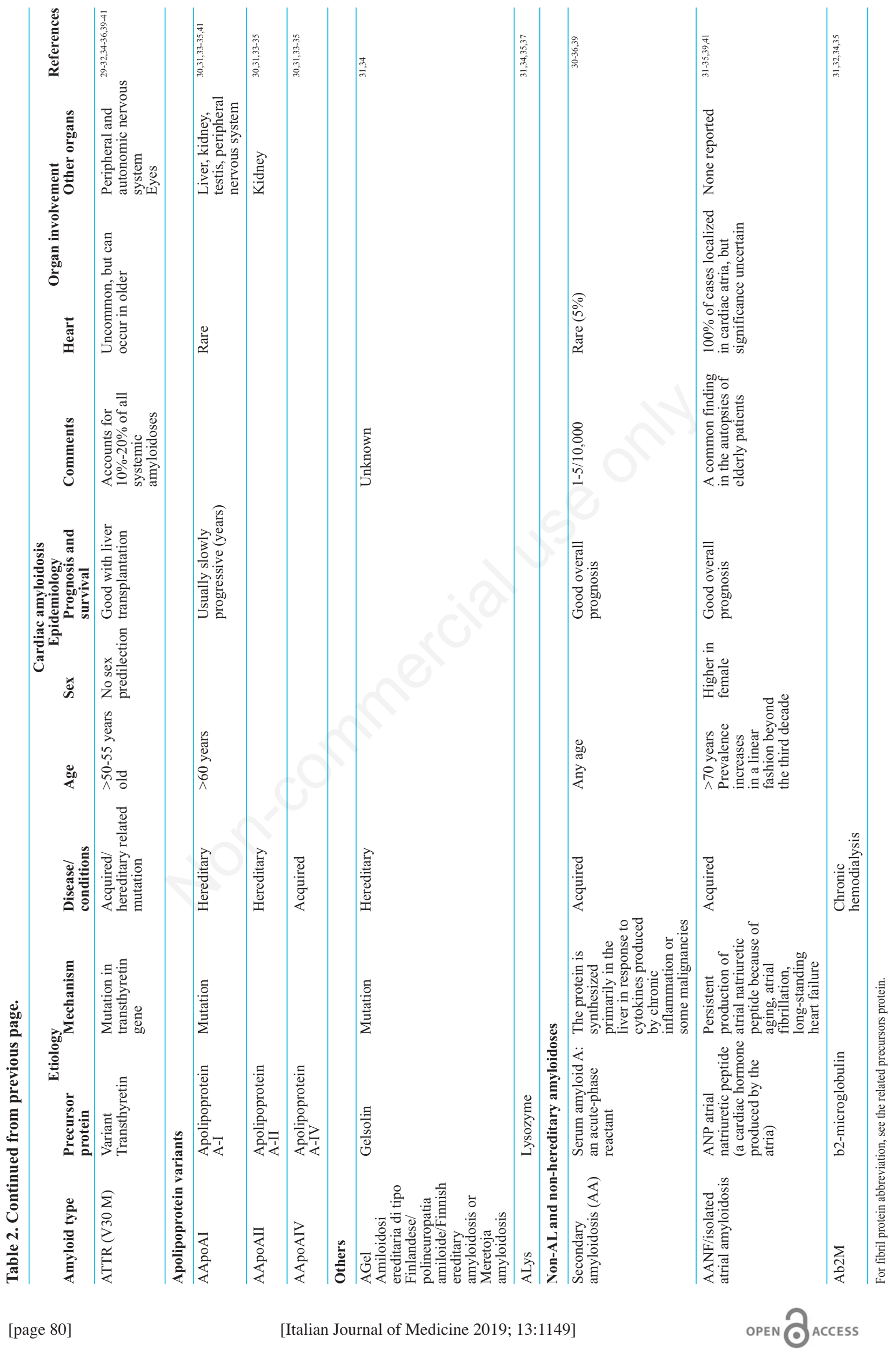


New high-sensitivity assay for measuring cTnT, hscTnT (high sensitivity cTnT to identify minimal cardiac damage) could improve the staging of $\mathrm{AL}$ amyloidosis.

The brain natriuretic peptide (BNP) and the protein that derived from $\mathrm{N}$-terminal cleavage of BNP, namely NT-pro BNP, have been consider reliable prognostic markers for cardiac amyloidosis, regardless of the nature of amyloid (AL or ATTR). According to the Mayo staging system, which is widely used for staging of $\mathrm{AL}$ amyloidosis, and according to Transthyretin Amyloidosis Outcomes Survey (THAOS), patients with higher BNP and NT-proBNP at the time of diagnosis, had a poor prognosis. ${ }^{73} \mathrm{Re}$ cently, Gillmore et al. described a novel diagnostic and staging tool for both ATTR wild type and mutate amyloidosis, they assessed estimated glomerular filtration rate and NT-proBNP which correlated well with overall survival. ${ }^{74}$ Very interestingly, the concentration of BNP/NT-proBNP in AL amyloidosis may fall dramatically within weeks after chemotherapy that substantially reduces the production of amyloidogenic light chains. An early transient increase in BNP/NT-proBNP may occur after treatment with the immunomodulatory drugs thalidomide and lenalidomide, which are frequently used in the management of AL amyloidosis. ${ }^{75}$

\section{Specific biomarkers for light chain amyloidosis}

Serum and urine immunofixation electrophoresis tighter with quantitative free light chain measurements give high sensitivity in diagnosing of monoclonal gammopathies and have become an important diagnostic tool in the diagnosis of AL amyloidosis. The difference between the serum levels of $\mathrm{k}$ and $\lambda$ free light chains is a major independent prognostic factor in AL amyloidosis. ${ }^{76}$

\section{Electrocardiogram}

In about $90 \%$ of patients with cardiac amyloidosis electrocardiogram is altered. The most common abnormalities include low QRS voltage (QRS amplitude $<1 \mathrm{mV}$ in all precordial or $<0.5 \mathrm{mV}$ in all limb leads) and pseudoinfarct pattern characterized by Q waves in precordial or inferior leads.

Conduction disturbances due to amyloid infiltration are also frequent. The myocardial conduction system involvement leads to complete or incomplete bundle branch block and atrioventricular block that could require pacemaker implantation. ${ }^{77}$

Other arrhythmias that may occur are atrial fibrillation and less frequently ventricular tachycardia.

\section{Echocardiography}

The echocardiogram represents a fundamental step in the diagnosis of cardiac amyloidosis. One of the most frequent features found in patients with amyloidosis is the presence of marked concentric biventricular wall thickness associated with reduced endocavitary size. The deposition of amyloid fibrils can sometimes be shown at the 2D echocardiogram with an aspect of granular sparkling pattern because of increased myocardial echogenicity.

However, left ventricular wall thickness is not specific of amyloidosis and a large series of diseases such as hypertrophic cardiomyopathy, hypertensive heart disease, aortic stenosis, sarcoidosis and others could manifest with cardiac hypertrophy. Anyway, the presence of increased thicknesses in addition to low voltages at the electrocardiogram orients the suspicion towards a storage disease.

Moreover, in some patients atrial septal thickening and valvular leaflet thickening could be found in addition to increased ventricular wall thickness. Deposition of amyloid in the left ventricle walls causes diastolic dysfunction in the presence of a normal pump function ( $\mathrm{FE}>50 \%$ ) in the early stages of the disease. The assessment of ventricular filling using transmitral Doppler can detect different degrees of diastolic dysfunction. In the early stage echo-doppler usually shows E/A ratio $<1$, on the contrary in the late stage mitral filling pattern is usually restrictive with E/A ratio $>2$ and increased filling pressures (E/E' increased). ${ }^{78,79}$

Other common echocardiographic findings are biatrial enlargement due to restrictive physiology, the presence of atrial thrombi independently from sinus rhythm and mild pericardial effusion.

As already mentioned above, amyloidosis shares echocardiographic features with some diseases characterized by cardiac hypertrophy and restrictive diastolic dysfunction. Sometimes differentiating the disorders could be a challenge, however the advent of speckle tracking technique allowed to simplify the diagnosis. In particular, amyloidosis is characterized by reduced left ventricular longitudinal strain with apical sparing. Indeed, recent studies have shown that septal longitudinal base-to-apex strain gradient $>2.1$ is able to differentiate cardiac amyloidosis from hypertensive heart disease and hypertrophic cardiomyopathy with high accuracy.

The differential diagnosis covered all types of cardiac conditions that mimic amyloid heart disease, or hypertrophic conditions: genetically determined conditions such as Fabry's disease and glycogen storage disease that manifested in pediatric patients; restrictive cardiomyopathy that is determined genetically with monogenic mutation or idiopathic with a clinical variable onset, myxomatous cardiomyopathy, hypertensive cardiomyopathy, hemochromatosis, aortic stenosis, sarcoidosis, infiltrative malignant disease. 


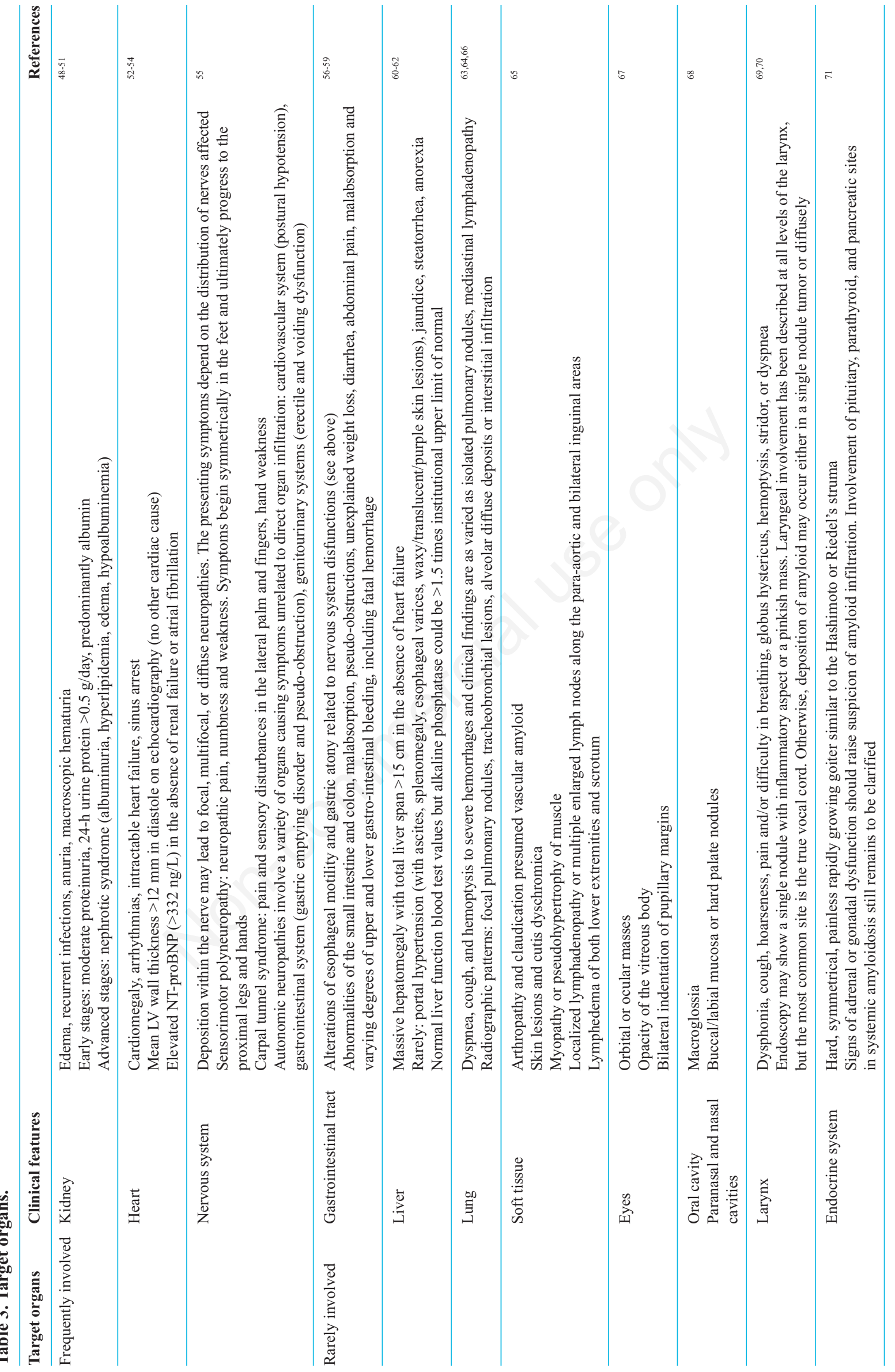




\section{Key messages}

- Electrocardiogram: i) low QRS voltage; ii) pseudoinfarct pattern ( $Q$ waves); iii) bundle branch block; iv) atrioventricular block; v) atrial fibrillation; vi) ventricular tachycardia.

- Echocardiogram: i) left and right ventricular wall thickness; ii) granular sparkling; iii) atrial septal increased wall thickness; iv) biatrial enlargement; v) atrial thrombi; vi) increased valve leaflet thickness; vii) mitral flow restrictive pattern; viii) mild pericardial effusion; ix) reduced left ventricular longitudinal strain with apical sparing.

\section{Scintigraphy}

It is known that myocardial scintigraphy with bone tracers is able to distinguish cardiac amyloidosis from other diseases, which are characterized by myocardial hypertrophy. Moreover, it has been widely demonstrated that some radiotracers, such as (99m) Tc-3,3diphosphono-1,2-propanodicarboxylic acid (99mTcDPD), (99m) Tc-pyrophosphate (99mTc-PYP) and 99mTc-labeled hydroxymethylene diphosphonate may be accurate to differentiate TTR-related amyloidosis from AL amyloidosis. ${ }^{80}$

Perugini et al. demonstrated that the 99tm DPD radiotracer uptake in myocardial tissue was present only in patients with TTR amyloidosis and not in AL amyloidosis. Nevertheless, other studies showed that even in AL forms uptake could occur in a small part. The reason why it seems that there is a greater uptake in patients with TTR amyloidosis has not been fully understood but it has been hypothesized that it could be related to a major increase in calcium in TTR forms.

Thanks to the ability of this method to accurately distinguish TTR amyloidosis from AL, it has been recently proposed that the diagnosis of TTR amyloidosis could be achieved without the need for histological confirmation in subjects with heart failure, echocardiogram/cardiac magnetic resonance (CMR) suggestive of cardiac amyloidosis, absence of monoclonal proteins and grade 2-3 of visual score of Perugini on myocardial scintigraphy.

\section{Cardiac magnetic resonance}

Magnetic resonance imaging is increasingly proposed as an imaging method of extreme importance in the diagnostic, prognostic and therapeutic setting of patients with cardiac amyloidosis.

The main magnetic resonance imaging (MRI) signal characteristics of this pathology include: i) diffuse and mostly symmetrical diffusion of the walls of the left ventricle, with frequent saving of the apical portion; ii) biventricular diastolic dysfunction, with systolic function and ejection fraction generally preserved only in the initial stages; iii) progressive increase of intraven- tricular pressures due to altered diastolic release with subsequent atrial dilatation and valvular insufficiency; iv) presence of pericardial impairment; v) widespread increase in signal intensity, with predominantly subendocardial distribution in post-contrast T1 images.

There are no studies and data sufficient to demonstrate superiority and a high predictive value of MRI compared to endomyocardial biopsy, which remains to date the gold standard for the definitive diagnosis of cardiac amyloidosis. ${ }^{81} \mathrm{~A}$ specific post-processing reconstruction technique recently introduced in MRI is the tissue tracking, that is the measurement of radial contractility of the myocardial portions (strain analysis), parallel evolution of speckle-tracking technique in echocardiography. Despite the few data still available, it seems that this analysis allows highlighting early and with excellent sensitivity the alterations compatible with cardiac amyloidosis. ${ }^{82}$

\section{Histological identification}

Once the disease is suspected, a precise diagnosis is needed and must be established by tissue histologic analysis. Biopsy tissue characterization is important to guide the appropriate treatment since different types of amyloidosis require different therapeutic approaches. ${ }^{83}$

When suspected, amyloidosis could be diagnosed through the so-called screening biopsy of rectum, salivary gland and fatty tissue. ${ }^{84}$ Among these sites for biopsy, salivary glands and rectum have come into disuse and were substituted with fatty tissue biopsy or fatty aspiration.

Congo red staining identifies amorphous reddish deposits at light microscopy, which exhibit apple-green birefringence at examination under polarized microscopy. Using sophisticate technology as confocal microscopy the histological stain will be more sensitive. ${ }^{85}$

Timely characterization can be achieved by targeting fatty tissue or the organ involved or suspected to be involved by taking a biopsy. Systemic forms of amyloid deposition can occur in the periumbilical subcutaneous fatty tissue, which can be sampled easily, it is well tolerated by patients and is less invasive allowing the identification and characterization of amyloid deposits before performing a targeted biopsy of the suspected involved organ. The organs of choice for biopsy could be heart, kidney, and liver according to symptoms.

Biopsy of subcutaneous fatty tissue (BSFT) is the easiest way to get a tissue sample to test for amyloid.

It is a highly sensitive method with sensitivity of $73 \%$ and specificity of $90 \%$. It can be used as a screening test in the early stage of the disease, also in asymptomatic patients it is useful in the diagnosis of amyloidosis AL and amyloidosis AA, however it has an important limitation having low sensitivity in pa- 
tients with small amyloid burden, or those with ATTR type of amyloidosis. ${ }^{86}$

The big advantage of the BSFT is the lack of contraindications and of risk of complications. ${ }^{85} \mathrm{Subcu}-$ taneous fatty tissue biopsy can be carried out also with fat pad fine needle aspiration (FPFNA) which has the same diagnostic sensitivity in cardiac AL amyloidosis, particularly in patients with a large whole-body amyloid burden as BSFT. The choice between BSFT and FPFNA is made according to the local experience.

Although the diagnostic sensitivity of FPFNA is substantially lower in transthyretin ( $45 \%$ for ATTRm and $15 \%$ for ATTRwt), particularly for ATTRwt, nevertheless, sometimes it may overcome the need for endomyocardial biopsy. Biopsy of subcutaneous fatty tissue is indicated especially in the systemic forms. If the fatty tissue is negative, we cannot exclude the presence of amyloidosis. Biopsy of the organ involved is mandatory to reach the correct diagnosis.

For cardiac amyloidosis, despite diagnostic improvements (CMR imaging, echocardiography with speckle tracking and skeletal scintigraphy) endomyocardial biopsy remains a gold standard in the diagnostic work-up of unexplained cardiac hypertrophy and for diagnosing cardiac amyloidosis.

Endomyocardial biopsies are not required in patients with biopsy-proven amyloidosis in other anatomical sites and having supportive echocardiographic or other non-invasive studies to suggest cardiac involvement.

Quantification of amyloid load at diagnosis is of prognostic relevance, indicating survival benefit of patients with an amyloid load $<20 \% .{ }^{87-91}$

\section{Stage III: amyloid characterization}

Once histologic tests document amyloid deposits and justify the diagnosis of amyloidosis, unambiguous amyloid typing is required to differentiate among the different forms.

Accurate identification and typing of amyloid proteins is crucial for determining appropriate treatment strategies and prognosis.

This can be performed with various histologcal thecniques and chemical approaches. Since 1996 the immunohistochemistry showed diagnostic pitfalls, for two or more antibodies for different fibril proteins. ${ }^{84}$ Many antobodies needed for characterization are not commercially available and as a consequence not standardized..$^{92}$ Immunohistochemistry, with commercially-available antibodies has a lower diagnostic performance and can lead to misdiagnoses. . $^{9-96}$

Whole blood protein electrophoresis, with or without immunofixation, is one of the old strategies but it can only distinguish between AL and non AL-typing amyloid even though it is inexpensive and non-invasive. ${ }^{97}$
Electron microscopy is usually applied to kidney biopsy in Italy, Europe and other Western countries. It is extremly helpful in the diagnosis of amyloidosis because amiloid fibrils have unique ultrastructural characteristrics. Amyloid fibrils have a tipical non-branching pattern and solid fibrils have a diameter between 7-12 nm which could differentiate them from other fibrillary or immunotactoid structures. This technique has become a gold standard in the diagnosis of amyloid fibrils. Moreover, immunogold electron microscopy is a technique that combines immunohistochemistry with electron microscopy. The latter technique ensures that the antibodies are reacting with amyloid and not with other proteins in the surrounding tissue, increasing the sensitivity and specificity of the technique itself. ${ }^{4}$ The limitation of this diagnostic tool is strictly influenced by the antibody panel, and by the availability of the electron microscope. In addition, it is also important to keep in mind that genetic mutations may make the target epitopes unavailable to antibody and result into a false negative sample. ${ }^{91}$ In our center and in the national amyloid referral center of Pavia the electron and immunoelectron microscopy is the gold standard adopted technique.

Proteomic analysis, both through mass spectrometry and protein separation by gel electrophoresis (2DPAGE/Western blot), represents a new interesting method both for discovering and typing protein amyloidotic fibrils, because they involve direct biochemical analysis of the specific protein deposited. ${ }^{98}$

Mass spectrometry could become a molecular technique able to identify rare or novel amyloid proteins even though the technique is complex and may be beyond the capability of many clinical laboratories, so it can be applied only in particular settings. One example is represented by the Mayo Clinic Hospital in the States, which is the referral center for all American cases. Their strategy is to offer a definitive diagnosis at a reasonable price in an short period of time, and to be able to identify the several variant mutation in the same protein. They apply routinely mass spectrometry to characterize the amiloid deposits and they are developing the new gold standard.

\section{Treatment}

Currently, there is no specific therapy that can cure amyloidosis and early diagnosis is essential to slow down the development of the amyloid protein.

Specific treatment depends on which type of amyloidosis is diagnosed and how many organs are affected.

Heart and kidneys are the most commonly involved organs in systemic amyloidosis. In particular, cardiac involvement is associated with an increased morbidity, treatment intolerance and poorer overall survival. Amyloid fibrils are considered responsible for the impairment of cardiomyocytes metabolism, causing oxidative 
stress, and eventually cell death, via a p38 mitogen-activated protein kinase signaling cascade.

Amyloid cardiomyopathy is better managed by a multidisciplinary approach, which allows the choice, through the contribution of various specialists, of a therapeutic strategy based on etiology and the disease timing. Focusing on the pathogenesis of the two main types of amyloidosis that affect the heart, light chain amyloidosis and transthyretin amyloidosis, we understand how a precise therapeutic intervention is required for the different types and each phase of the disease (Figure 3).

If the diagnosis of cardiac involvement is made early, the goal will be to prevent cardiac impairment while, to intervene with supportive care in the terminal stages will be the only chance left.

\section{Treatment of light chain amyloidosis}

The treatment of AL amyloidosis must involve suppression of the plasma cell clone responsible for the production of the toxic immunoglobulin light chain. Chemotherapy represents the first option improving organ function, quality of life and prolonging survival. As a first-line therapy in AL amyloidosis, alkylator-based treatment in combination with a corticosteroid, as the combination of melphalan and prednisone, is indicated..$^{99}$

Recently, other different approaches targeting the amyloid deposits have been introduced.

For example, proteasome inhibitors and immunomodulators have an excellent activity in both frontline and relapsed settings in AL amyloidosis. ${ }^{100}$

Cyclophosphamide, bortezomib, and dexamethasone have shown deep responses. Autologous transplantation of stem cells has surely to be considered as an option, but it is also related to an unacceptable mortality, because of the patient's fragility.

For this reason, it is important to underline that the treatment of AL amyloidosis should be risk-adapted because not all patients are able to face aggressive treatments. The individual risk depends on the stage of illness, considering the biohumoral values, the eligibility to bone marrow transplant and the New York Heart Association (NYHA) class. These parameters allow the clinician to identify a low-risk, an intermediate-risk, and a high-risk group of patients. ${ }^{101}$

As far as future non-chemotherapy approaches are concerned, the anthracycline 4'-iodo-4'-deoxy-doxorubicin and the antibiotic doxycycline, with a similar molecular structure, promote the reduction of the amyloid load in vitro. In particular, doxycycline influences proliferation, migration, apoptosis, and matrix remodeling of mammalian cells. Polyphenols may be useful in order to inhibit the fibrillogenesis, and heir utilization is still under investigation. Another important class to consider is the anti-amyloid-antibodies class. The mon- oclonal antibody called NEOD001 seems to accelerate the regression of AL kappa amyloidomas in mice, with high percentage of cardiac and renal responses. ${ }^{43}$

\section{Treatment of transthyretin amyloidosis}

Orthotopic liver transplantation has got the rationale to suppress the production of mutant TTR, predominantly produced by the liver. It could be combined with cardiac transplantation, demonstrating promising results. In particular, this combination seems to allow superior survival outcomes. When transplantation cannot be the therapeutic choice, as in the elderly, a pharmacologic approach is needed. Tafamidis and diflunisal, which are stabilizers of TTR tetramers, are a valid option. ${ }^{102}$ Tolcapone, approved by the Food and Drug Administration for Parkinson's disease, is a TTR aggregation inhibitor, which binds specifically to TTR in human plasma and stabilizes the native tetramer in vivo in mice and humans, also having an effect on the TTR cytotoxicity. AG10, is another potent and selective kinetic stabilizer of TTR, able to prevent dissociation of V122I-TTR in serum samples obtained from patients with familial amyloid cardiomyopathy. ${ }^{103}$

The development of gene therapies to suppress TTR expression, as small interfering RNA and antisense oligonucleotide, may prevent the progression of the disease.

In the advanced pathogenesis stages, as for $\mathrm{AL}$ amyloidosis, the anthracycline 4'-iodo-4'-deoxy-doxorubicin and the antibiotic doxycycline can be used.

A natural compound called tauroursodeoxycholic acid, reducing cytotoxicity in many neurodegenerative diseases, has been found to slow down the amount of TTR toxic aggregates. To end this quick summary about treatments, we cannot omit the immunotherapies. PRX004 is a synthetic antibody designed to bind to non-native misfolded forms of TTR with the goal of potentially preventing deposition and promoting clearance of TTR aggregates. ${ }^{104}$

\section{Symptomatic and supportive therapy}

In the terminal stages, both in AL and TTR amyloidosis, when the patient has developed cardiac insufficiency often in the setting of nephrotic syndrome, the only weapon in clinician's hands is using symptomatic and palliative care.

The mainstay of heart-failure treatment are diuretics, both oral and intravenous, salt restriction and other nutritional supports. Attention must be paid on the fact that cardiac function is preload-dependent and so the reduction of intravascular volume must be avoided. The efficacy of drugs, which are routinely used in patients with heart failure, is not tested specifically in the treatment of cardiac amyloidosis.

For example, the angiotensin-converting enzymes 


\section{Transthyretin Amyloidosis}

THERAPY
Liver
transplantation
TTR silencers:
ASO, siRNA
Retinal laser
photocoagulation
Gene conversion
therapy
(single-stranded
oligonucleotides)

TTR stabilizer: Diflunisal, Tafamidis, Tolcapone, AG 10

$$
\text { Tolcapone, AG } 10
$$

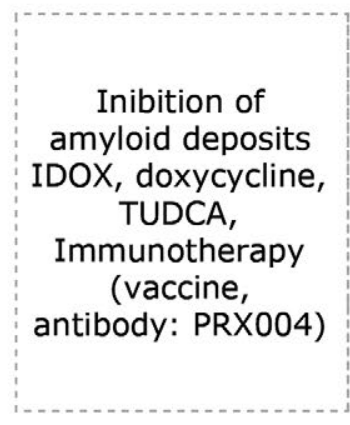

$\Rightarrow$

Liver, eye, brain production and secretion of TTR

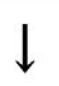
$\Rightarrow$

\section{PATHOGENESIS}
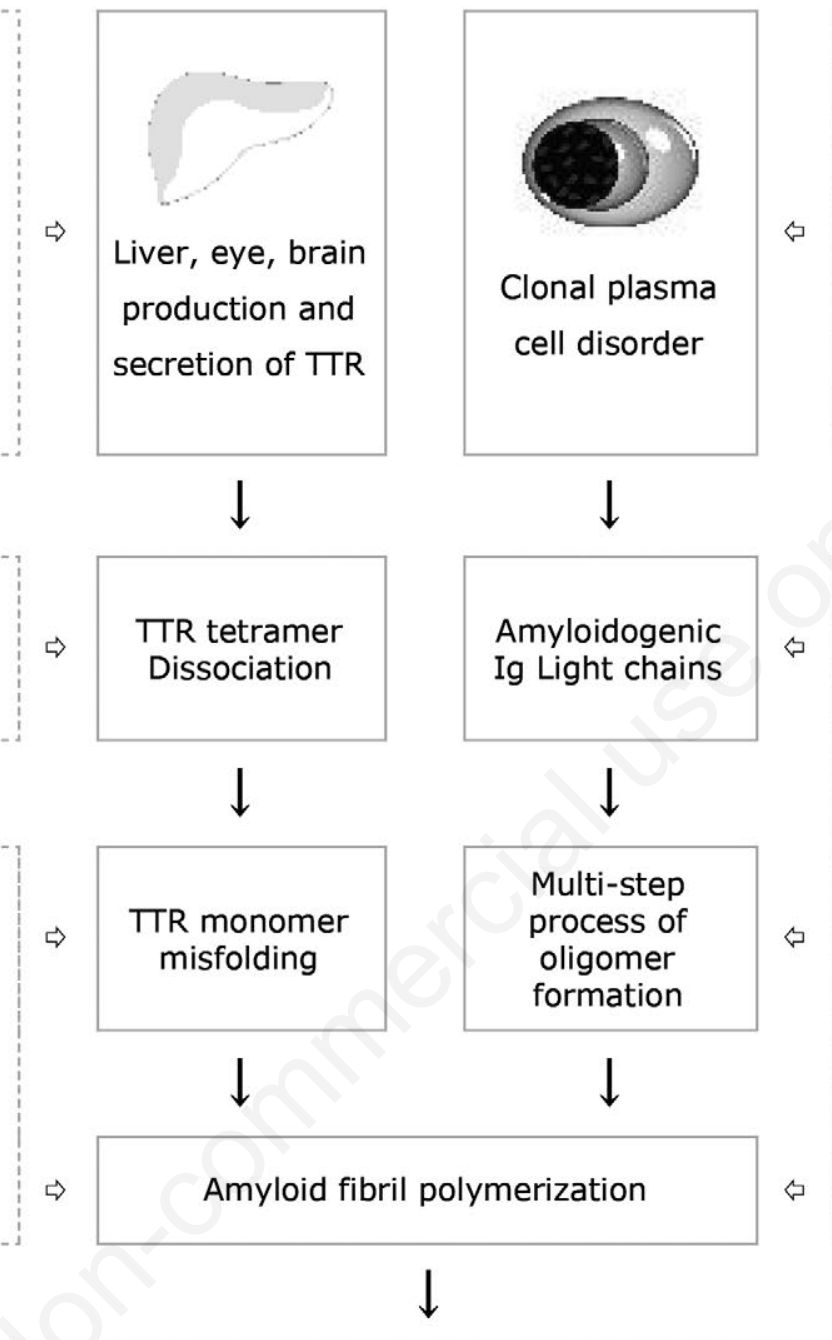

ORGAN DISFUCTION

AND DEPOSITION

CARDIACAMYLOIDOSIS

\section{Light chain Amyloidosis}

PATHOGENESIS

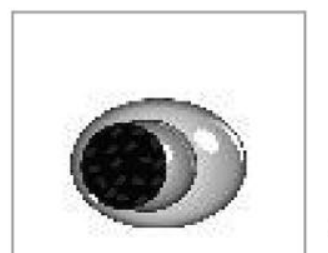

Clonal plasma cell disorder

Amyloidogenic Ig Light chains

Multi-step process of oligomer formation Anti-amyloid antibody

(NEOD001)
Antiplasma cell therapies (Alkylating agents: Melphalan, Cyclophosphamide; Proteasome inhibitors: Bortezomib, Ixazomib; Immunomodulators: Pomalidomide;

Anti-CD38 monoclonal antibody: Daratumumab)

\section{4-iodo-4}

deoxy-doxorubicin, doxycycline

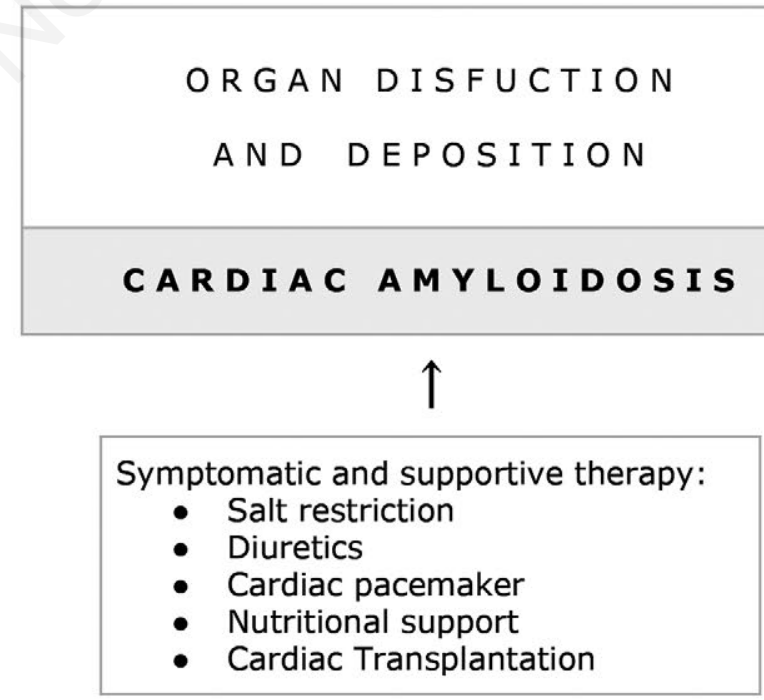

Figure 3. Treatment of light-chain and hereditary transthyretin amyloidosis. 
inhibitors can lead to significant hypotension even at low doses, due to the reduction in cardiac preload. In addition, $\beta$-blockers may produce bradycardia and hypotension, and are poorly tolerated, furthermore, calcium channel blockers should be avoided, due to their negative inotropic effect. Digoxin can bind with amyloid fibrils, leading to locally high drug concentrations. ${ }^{104,105}$

Placement of a left ventricular assist device may be useful in patients with recurrent arrhythmic syncope and also as a bridge to heart transplantation. Cardiac transplant is indicated in patients with irreversible, end-stage organ dysfunction and in young patients with isolated cardiac involvement and severe heart failure followed by autologous stem-cell transplantation, or combined with liver transplantation, as we mentioned before.

\section{Conclusions}

Cardiac amyloidosis is a malignant disease and when it manifests with signs and symptoms it is in an advanced stage. Although it is classified as a rare disease, invasive and non-invasive diagnostic tools have improved our ability to identify the location of amyloid deposits and increasing the number of affected patients. Moreover, the aging of population potentially increases the cases of TTR amyloidosis and imposes the differentiation between ATTRwt and ATTRm.

Early diagnosis is mandatory to stop the progression of the disease and improve the outcome. Many pharmacological treatments are offered today to treat efficaciously patients affected by amyloidosis.

New biohumoral markers together with new tissue characterization tools (with proteomics or mass spectrometry) direct towards a personalized target therapy, which is the best strategy to cure amyloidosis.

\section{References}

1. Malyszko J, Kozlowska K, Malyszko JS. Amyloidosis: a cancer-derived paraproteinemia and kidney involvement. Adv Med Sci 2017;62:31-8.

2. Kyle RA. Amyloidosis: a convoluted story. Br J Haematol 2001;114:529-38.

3. Riek R, Eisenberg DS. The activities of amyloids from a structural perspective. Nature 2016;539:227-35.

4. Leung N, Nasr SH, Sethi S. How I treat amyloidosis: the importance of accurate diagnosis and amyloid typing. Blood 2012;120:3206-13.

5. Chiti F, Dobson CM. Protein misfolding, amyloid formation, and human disease: a summary of progress over the last decade. Annu Rev Biochem 2017;86:27-68.

6. Sipe JD, Benson MD, Buxbaum JN, et al. Amyloid fibril proteins and amyloidosis: chemical identification and clinical classification International Society of Amyloidosis 2016 Nomenclature Guidelines. Amyloid 2016; 23:209-13.

7. WHO-IVIS Nomenclature Sub-Committee. Nomenclature of amyloid and amyloidosis. Bull World Health Organ 1993;71:105-12.

8. Westermark P, Benson MD, Buxbaum JN, et al. A primer of amyloid nomenclature. Amyloid 2007;14: 179-83.

9. Gillmore JD, Maureer MS, Falk RH, et al. Non biopsy diagnosis of cardiac tranthyretin amyloidosis. Circulation 2016;133:2404-12.

10. WHO-IUIS Nomenclature Sub-committee. Nomenclature of amyloid and amyloidosis. Bull World Health Organ 1993;71:105-12.

11. Nasr SH, Dasari S, Hasadri L, et al. Novel type of renal amyloidosis derived from apolipoprotein-CII. J Am Soc Nephrol 2017;28:439-45.

12. Merlini G, Bellotti V. Molecular mechanisms of amyloidosis. N Engl J Med 2003;349:583-96.

13. Bensen MD, James S, Scott K, et al. Leukocyte chemotactic factor 2: a novel renal amyloid protein. Kidney Int 2008;74:218-22.

14. Kyle MA, Gertz MA. Primary systemic amyloidosis: clinical and laboratory features in 474 cases. Sem H Ematol 1995;32:45-59.

15. Dogan A. Amyloidosis: insights from proteomics. Annu Rev Pathol 2017;12:277-304.

16. Maleszewski JJ. Cardiac amyloidosis: pathology, nomenclature, and typing. Cardiovasc 2015;24:343-50.

17. Banypersad SM, Moon JC, Whelan C, et al. Updates in cardiac amyloidosis: a review. J Am Heart Assoc 2012; $1: \mathrm{e} 000364$.

18. Shah KB, Inoue Y, Mehra MR. Amyloidosis and the heart: a comprehensive review. Archiv Intern Med 2006; 166:1805-13.

19. Mohty D, Damy T, Cosnay P, et al. Cardiac amyloidosis: updates in diagnosis and management. Archiv Cardiovasc Dis 2013;106:528-40.

20. Kumar S, Dispenzieri A, Lacy MQ, et al. Revised prognostic staging system for light chain amyloidosis incorporating cardiac biomarkers and serum free light chain measurements. J Clin Oncol 2012;30:989-95.

21. Patel KS, Howkins PN. Cardiac Amyloidosis: where are noe today?. J Intern Med 2015;278:126-44.

22. De Lazzari M, Fedrigo M, Migliore F, et al. Nonamyloidotic light chain cardiomyopathy: the arrhythmogenic magnetic resonance pattern. Circulation 2016; 133:1421-3.

23. Falk RH, Alexander KM, Liao R, Dorbala S. AL (lightchain) cardiac amyloidosis: a review of diagnosis and therapy. J Am Coll Cardiol 2016;68:1323-41.

24. Milani P, Basset M, Russo F, et al. Patients with lightchain amyloidosis and low free light-chain burden have distinct clinical features and outcome. Blood 2017;130: 625-31.

25. Gillmore JD, Wechalekar A, Bird J, et al. Guidelines on 
the diagnosis and investigation of AL amyloidosis. $\mathrm{Br} \mathrm{J}$ Haematol 2015;168:207-18.

26. Nienhuis HL, Bijzet J, Hazenberg BP. The prevalence and management of systemic amyloidosis in Western countries. Kidney Dis (Basel, Switzerland) 2016;2:10-9.

27. Grogan M, Scott CG, Kyle RA, et al. Natural history of wild-type transthyretin cardiac amyloidosis and risk stratification using a novel staging system. J Am Coll Cardiol 2016;68:1014-20.

28. Steiner I, Hajkova P. Patterns of isolated atrial amyloid: a study of 100 hearts on autopsy. Cardiovasc Pathol 2006;15:287-90.

29. Falk RH, Alaxander KM, Liao R, et al. AL (light chain) cardiac amyloidosis. J Am Coll Cardiol 2016;68:1323-41.

30. Garcìa-Pavìa P, Tomè-Esteban MT, Rapezzi C. Amyloidosis. Also a heart disease. Rev Esp Cardiol 2011;64: 797-808.

31. Wang Y, Zhang Y. Amyloid and immune homeostasis. Immunology 2018;223:288-93.

32. Shah KB, Inoue Y, Mehra MR. Amyloidosis and the heart: a comprehensive review. Arch Int Med 2006; 166:1805.

33. Kapoor P, Thenappan T, Singh E, et al. Cradiac Amyloidosis: a practical approach to diagnosis and management. Am J Med 2011;124:1006-15.

34. Maleszewski JJ. Cardiac amyloidosis: pathology, nomenclature and typing. Cardiov Pathol 2015;24:343-50.

35. Rapezzi C, Lorenzini M, Longhi S, et al. Amyloidosis: the great pretender. Heart Fail Rev 2015;20:117-24.

36. Mohty D, Dami T, Cosnay P, et al. Cradiac amyloidosis: updates in diagnosis and management. Arch Cardiovasc Dis 2013;106:528-40.

37. Nasr SH, Dasari S, Mills JR, et al. Hereditary lysozyme amyloidosis variant p.leu102ser associates with unique phenotype. J Am Soc Nephrol 2017;28:431-8.

38. Grogan M, Dispenzieri A, Gertz MA. Light chain cardiac amyloidosis: strategies to promote early diagnosis and cardiac responde. Heart 2017;103:1065-72.

39. Chakraborty R, Muchtar E, Gertz MA. Newer therapies for amyloid cardiomyopathy. Curr Heart Failure Rep 2016;13:237-46.

40. Wechalerkar AD, Gillmore JD, Hawkins PN. Systemic amyloidosis. Lancet 2016;387:2641-54.

41. Banypersad SM, Moon JC, Whelan C, et al. Updates in cardiac amyloidosis: a review. J Am Heart Assoc 2012; 1:e000364.

42. Alexander KM, Falk RH. V122I TTR Cardiac Amyloidosis in patients of african descent: recognizing a missed disease or the dog that didn't bark?. Circ Heart Fail 2016;9:e003489.

43. Palladini G, Merlini G. What is new in diagnosis and management of light chain amyloidosis?. Blood 2016; 128:159-68.

44. Bodez D, Galat A, Guellich A, et al. [Cardiac amyloidosis: How to recognize them and manage them?]. Presse Med (Paris, France: 1983) 2016;45:845-55.

45. Kapoor P, Thenappan T, Singh E, et al Cardiac amyloi- dosis: a practical approach to diagnosis and management. Am J Med 2011;124:1006-15.

46. Kholova I, Niessen HW. Amyloid in the cardiovascular system: a review. J Clin Pathol 2005;58:125-33.

47. Dispenzieri A, Gertz MA, Kyle RA, et al. Serum cardiac troponins and $\mathrm{N}$-terminal pro-brain natriuretic peptide: a staging system for primary systemic amyloidosis. J Clin Oncol 2004;22:3751-7.

48. Nasr SH, Said SM, Valeri AM, et al. The diagnosis and characteristics of renal havy-chain and havy/light-chain amyloidosis and their comparison with renal light-chain amyloidosis. Kidney Int 2013;83:463-70.

49. Khalighi MA, Wallace WD, Palma-Diaz MF. Amyloid nephropathy. Clin Kidney 2014;7:97-106.

50. Basnayake KS, Stringer SJ, Hutchison CA, Cockwell P. The biology of immunoglobulin free light chains and kidney injury. Kidney Int 2011;79:1289-301.

51. Gertz MA, Lacy MQ, Dispenzieri A, Hayman SR. Amyloidosis: diagnosis and managment. Clin Lymph Myel 2005;6:208-19.

52. Munjewar C, Agrawal R, Sharma S. Cardiac amyloidosis: a report of two cases. Indian Heart J 2014;66:473-6.

53. Dubrey SW, Hawkins PN, Falk RH. Amyloid disease of the heart: assessment, diagnosis and refferal. Heart 2011;97:75-84.

54. Priyamvada PS, Morkhandikar S, Srinivas BH, Parameswaran S. Heavy and light chain amyloidosis presenting as a complete heart block: a rare presentation of a rare disease. Indian J Nephrol 2015;25:106-9.

55. Shin SC, Ribison-Papp J. Amyloid neuropathies. Mt Sinai J Med 2012;79:733-48.

56. Iida T, Yamano H, Nakase H. Systemic amyloidosis with gastrointestinal involvement: diagnosis from endoscopic and histological views'. J Gastroenterol Hepatol 2018;33: 583-90.

57. Rowe K, Pankow J, Nehme F, Salyers W. Gastrointestinal Amylodosis: review of the literature. Cureus 2017; 9:e1228.

58. Ebert EC, Nagar M. Gastrointestinal manifestation of amyloidosis. Am J Gastroenterol 2008;103:776-87.

59. Cowan AJ, Skinner M, Seldin DC, et al. Amyloidosis of the gastrointestinal tract:1 13 year, single-center, refferal experience. Haematologica 2013;98:141-6.

60. Ye L, Shi H, Wu HM, Wang FY. Primarily isolated hepatic involvement of amyloidosis: a case report and overview. Medicine (Baltimore) 2016;95:e5645.

61. Sonthalia N, Jain S, Pawar S, et al. Primary hepatic amyloidosis: a case report and review of literature. World J Hepatol 2016;8:340-4.

62. Shin YM, Hepatic amyloidosis. Korean J Hepatol 2011; 17:80-3.

63. Khoor A, Myers JL, Tazelaar HD, Kurtin PJ. Amyloidlike pulmonary nodules, including localized light-chain deposition: clinicopathological analysis of three cases. Am J Clin Pathol 2004;121:200-4.

64. Khoor A, Colby TV. Amyloidosis of the lung. Arch Pathol Lab Med 2017;141:247-54. 
65. Park J, Jeong HW, Lee J, et al. Lymphedema associated with primary amyloidosis: a case study. Ann Rehabil Med 2017;41:887-91.

66. Milani P, Basset M, Russo F, et al. The lung in amyloidosis. Eur Respir Rev 2017;26:pii170046.

67. Manaa-Alkatan H, Al-Mohizea A, Alsuhaibani A. A case of localized amyloidosis of the eyelid misdiagnosed as recurrent chalazion. Saudi J Ophthalmol 2017;31-180-2.

68. Matsuo FS, Barbosa de Paulo LF, Servato JP, et al. Involvement of oral tissuesby AL amyloidosis: a literature review and report of eight new cases. Clinic Oral Investig 2016;20:1913-20.

69. Behnoud F, Baghbaninan F. Isolated laryngeal amyloidosis. Iran J Otorhinolaryngol 2013;25:49-52

70. Yiotakis I, Georgolios A, Charalabopoulos A, et al. Primary localized laryngeal amyloidosis presenting with hoarseness and dysphagia: a case report. J Med Case Rep 2009:3:9049.

71. Ozdemir D, Dagdelen S, Erbas T. Endocrine involvement in systemic amyloidosis. Endocr Pract 2010;16:1056-63.

72. Quian G, Wu C, Zhang Y, et al. Prognostic value of High-sensitivity cardiac troponin $\mathrm{T}$ in patients with andomyocardial-biopsy proven cardiac amyloidosis. J Geriatr Cardiol 2014;11:136-40.

73. Kristen AV, Maurer MS, Rapezzi C, et al. Impact of genotype and phenotype of cardiac biomarkers in patients with transthyretin amyloidosis-Report from ranthyretin Amyloidosis outcome survay (THAOS). PLoS One 2017;12:1-17.

74. Gillmore JD. A new staging system from cardiac transthyretin amyloidosis. Eur Heart J 2018;39: 2799-806.

75. Chiti F, Dobson CM. Protein misfording, Amyloid formation and human disease: a summary of progress ovrer the last decade. Ann Rev Biochem 2017;86:27-68.

76. Kumar S, Dispenzieri A, Lacy MQ, et al. Revised prognostic system for light chain amyloidosis incorporating cardiac biomarkers and serum free light chain measurements. J Clinic Oncol 2012;30:989-95.

77. Murtagh B, Hammill SC, Gertz MA, et al. Electrocardiographic findings in primary systemic amyloidosis and biopsy-proven cardiac involvement. Am J Cardiol 2005;95:535-7.

78. Phelan D, Collier P, Thavendiranathan $\mathrm{P}$, et al. Relative apical sparing of longitudinal strain using two-dimensional speckle-tracking echocardiography is both sensitive and specific for the diagnosis of cardiac amyloidosis. Heart 2012;98:1442-8.

79. Cueto-Garcia L, Reeder GS, Kyle RA, et al. Echocardiographic findings in systemic amyloidosis: spectrum of cardiac involvement and relation to survival. J Am Coll Cardiol 1985;6:737-43.

80. Perugini E, Guidalotti PL, Salvi F, et al. Noninvasive etiologic diagnosis of cardiac amyloidosis using $99 \mathrm{mTc}-$ 3,3-diphosphono-1,2-propanodicarboxylic acid scintigraphy. J Am Coll Cardiol 2005;46:1076-84.

81. Martinez-Nohano A, Treibel TA, Adbel-Gadir A, et al.
Magnetic resonance in transthyretin cardiac amyloidosis. J Am Coll Cardiol 2017;25:466-77.

82. Fontana M, Chung R, Hawkins PN, Moon JC. Cardiovascular magnetic resonance for amyloidosis. Heart Fail Rev 2015;20:133-44.

83. Leone O, Veinot JP, Angelini A, et al. 2011 consensus statement on endomyocardial biopsy from the Association for European Cardiovascular Pathology and the Society for Cardiovascular Pathology. Cardiovasc Pathol 2012;21:245-74.

84. Rocken C, Schwotzen EB, Linke RP, Saeger W. The classification of amyloid deposits in clinico-pathological practice. Histopathology 1996;29:325-35.

85. Castellani C, Fedrigo M, Frigo AC, et al. Application of confocal laser scanning microscopy for the diagnosis of amyloidosis. Virchows Arch 2017;470:455-63.

86. Quarta CC, Gonzalez-Lopez E, Gilbertson JA, et al. Diagnostic sensitivity of abdominal fat aspiration in cardiac amyloidosis. Eur Heart J 2017;38:1905-8.

87. Kollikowski AM, Kahles F, Kintsler S, et al. In vivo quantification of amyloid burden in TTR-related cardiac amyloidosis. Intract Rare Dis Res 2017;6:291-4.

88. Kristen AV, Brokbals E, Aus dem Siepen F, et al. Reply: Should histologic determination of amyloid load determine management decisions in light-chain amyloidosis? J Am Coll Cardiol 2016;68:2494-5

89. Kristen AV, Brokbals E, Aus dem Siepen F, et al. Cardiac amyloid load: a prognostic and predictive biomarker in patients with light-chain amyloidosis. J Am Coll Cardiol 2016;68:13-24.

90. Patel AR, Kramer CM. Role of cardiac magnetic resonance in the diagnosis and prognosis of nonischemic cardiomyopathy. JACC Cardiovasc Imaging 2017;10: 1180-93.

91. Falk RH, Quarta CC, Dorbala S. How to image cardiac amyloidosis. Circ Cardiovasc Imaging 2014;7:552-62.

92. Kebbel A, Rocken C. Immunohistochemical classification of amyloid in surgical pathology revised. Am J Surg Pathol 2006;30:673-83.

93. Fernandez de Larrea C, Verga L, Morbini P, et al. A practical approach to the diagnosis of systemic amyloidoses. Blood 2015; 125:2239-41.

94. Schonland SO, Hegenbart U, Bochtler T, et al. Immunohistochemistry in the classification of systemic forms of amyloidosis: a systematic investigation of 117 patients. Blood 2012;119:488-93.

95. Satoskar AA, Efebera Y, Hasan A, et al. Strong transthyretin immunostaining: potential pitfall in cardiac amyloid typing. Am J Surg Pathol 2011;35: 1685-90.

96. Satoskar AA, Burdge K, Cowden DJ, et al. Typing of amyloidosis in renal biopsies: diagnostic pitfalls. Arch Pathol Lab Med 2007;131:917-22.

97. Milani P, Basset M, Russo F, et al. Patients with lightchain amyloidosis and low free light-chain burden have distintic clinical features and outcome. Blood 2017; 130:625-31 
98. Vrana JA, Gamez JD, Madden BJ, et al. Classification of amyloidosis by laser microdissection and mass spectrometry-based proteomic analysis in clinical biopsy specimens. Blood 2009;114:4957-9.

99. Mahmood S, Palladini G, Sanchorawala V, Wechalekar A. Update on treatment of light chain amyloidosis. Haematologica 2014;99:209-21.

100. Palladini G, Merlini G. Systemic amyloidoses: what an internist should know. Eur J Intern Med 2013;24:729-39.

101. Sanchorawala V, Palladini G, Kukreti V, et al. A phase $1 / 2$ study of the oral proteasome inhibitor ixazomib in relapsed or refractory AL amyloidosis. Blood 2017; 130:597-605.
102. Adams D, Suhr OB, Hund E, et al. First European consensus for diagnosis, management, and treatment of transthyretin familial amyloid polyneuropathy. Curr Opin Neurol 2016;29:S14-26.

103. Chakraborty R, Muchtar E, Gertz MA. Newer therapies for amyloid cardiomyopathy. Curr Heart Fail Rep 2016;13:237-46.

104. Palladini G, Milani P, Merlini G. Novel strategies for the diagnosis and treatment of cardiac amyloidosis. Expert Rev Cardiovasc Ther 2015;13:1195-211.

105. Donnelly JP, Hanna M. Cardiac amyloidosis: An update on diagnosis and treatment. Cleve Clin J Med, 2017; 84:12-26. 